\title{
Junior Secondary School Pupils' Perception of the Relevance of Environmental Issues: Implications for Science Educators
}

\author{
Anderson, I. K. \\ Department of Science Education, Faculty of Science Education, Winneba, Ghana. \\ Email: ishkandy@yahoo.com
}

\begin{abstract}
This study focuses on how the Ghanaian youth would want to associate with some environmental matters regarding science and technology learning using the Relevance of Science Education (ROSE) survey questionnaire; and is also aimed at providing implications for science educators. The results reported in this study are an extract from the author's thesis and also from Ghanaian data which are aspects of much larger ROSE data collected from about 40 countries. The study involved a sample of 1027 Junior Secondary School (JSS) 3 or ninth graders (551 boys and 476 girls) drawn from all the 12 districts in the Central Region of Ghana. The study draws on only one of the themes covered by the ROSE instrument and pupils were asked to indicate the extent to which they agree with 18 statements on a 4-point Likert-type scale which goes from 'Disagree' to 'Agree'. The responses were analysed using SPSS and Excel. Descriptive statistics was conducted on the data and an independent sample 2-tailed t-test was used to explore the statistical significance of the differences in the items' mean at $p \leq 0.05$. On the average, the results suggest that the majority of pupils in the sample, irrespective of the gender shared almost similar sentiments towards environmental protection issues and to a large extent, placed the same items on top as well as at the bottom of their priorities. An interesting aspect of pupils' concerns for the environment was their optimism about the future of the globe. The study suggests the need for science educators to consider pupils' views when teaching environmental related issues.
\end{abstract}

Keywords: relevance of science education, environmental protection issues

\section{Introduction}

The present generation of young people is growing at a time that the earth faces numerous and different types of environmental degradation as a result of humans' engagement with nature. The major environmental degradation occurring in Ghana as a developing country includes land degradation, deforestation, and water and air pollution. Others are uncontrolled bushfires, fuel wood extraction and unsanitary condition of our surroundings. These are some of the key issues that challenge the Environmental Action Plan (EAP) of successive governments in Ghana. The action plan provides a framework for interventions deemed necessary to safeguard the environment. The EAP has been and continues to be implemented but with little success. This implies that the current challenges in the environmental protection strategies require the full participation of all citizens, and not to be seen as responsibility of only scientists, politicians and researchers.

The citizenry must be aware and well informed about the values of sustainable environmental practices. A well informed citizenry in a way might work towards such goals:

- appreciate the relationship between human and the environment;

- be aware of the limitations which the environment impose on human's actions and activities as well as the opportunities which it offers to human for the improvement and enhancement of the quality of life;

- understand the special problems of the local and the national environment and the most effective ways of dealing with these problems; and

- to understand and appreciate the fact that it is the responsibility of every generation to safeguard the environment. 
Environmental education which is a component of EAP is seen as a major player leading to the attainment of the stated goals.

An important outcome of science and technology education is to have learners make informed decisions about and take informed actions on personal lifestyle choices, local challenges, global climatic changes, risks and benefits, and populations, resources and environments (NRC, 1996). This means that science and technology education has a key role to play in preparing young people to cope with the emergent environmental challenge issues. Environmental education, which stands currently as a part of science and technology education programmes, might help in the development of individuals to demonstrate responsible environmental behaviour towards their environment in order to develop a sustainable environment. To this end, continuous and detailed educational programme for environmental education in the basic and second cycle schools were prepared and integrated into the curricula of schools. An audit of assessment system in schools and teacher training colleges has established that teaching/learning is restricted to the acquisitions of cognitive skills to the neglect of the development of responsible environmental attitudes (EPA, 1995).

Environmental practices, however, go far beyond acquisition of environmental knowledge based on scientific ideas and concepts (cognitive factors), but must also relate to affective dimensions, such as environmental attitude, concern, beliefs, values and emotional disposition, which play a very important role in learning outcomes (Schreiner and Sjøberg, 2003). Learning of science therefore must encompass also attitudinal and motivational factors. It has also been suggested elsewhere that prior knowledge as well as values, beliefs, attitudes, concerns and emotional disposition of learners might influence their understandings about and capabilities to act towards the environment (Huang and Yore, 2003). It is therefore essential to understand the attitudes, beliefs and concerns that might prevent individuals from recognising and using their possibilities to act. I am of the view that education in general should equip learners with requisite knowledge and skills for themselves to decide how, where and when to apply the gained competences. Teaching of environmental education therefore needs to be based on pupils' knowledge, attitudes towards and conceptions of the environmental protection issues.

\section{Some studies in children's perception about environmental issues}

Empowering learners to be responsible towards the environment should be one of the important goals of science education. Unfortunately, much attention of science education researchers have been drawn into studies in pupils' alternative conceptions of science content to the neglect of pupils' perspectives regarding environmental matters (Schreiner and Sjøberg, 2004; Reid and Sa'di, 1997). However, attempts have been made in this direction for some time now.

Schreiner and Sjøberg (2003) conducted a study on how young people relate to environmental challenges with 1200 fifteen-year-old Norwegian pupils as part of ROSE and found from preliminary analysis that pupils did not seem pessimistic about the global future. They trust in themselves that they personally can influence what happens with the environment. The study also confirmed the pupils' general concern about the environment but they showed low interest to learn about environmental protection at school.

A study was conducted in the United Kingdom with elementary school children with ages between 11 and 13 years. The result indicated that both genders showed positive attitudes towards nature and the environment. They also identified pollution, deforestation, and extinction of species as some of many problems confronting the earth, and accepted the individual responsibility for the environment and not others or the government. The result also 
showed no notable gender differences regarding environmental issues (Bonnet and Williams, 1998).

Some comparative studies were carried out among children from different cultures. The findings appeared to suggest that environmental issues are a cross-cultural concern. For example, the environmental views of 12-year-old German and Russian adolescents were investigated. Adolescents from both countries showed similar high emotional dispositions towards environmental problems (Szagum and Pavlov, 1995). Results from a study of grade 5 children from Canada and Taiwan also revealed that children from both countries expressed positive environmental behaviour, positive attitudes towards the environment, high concern about the environmental problems, high emotional disposition towards current environmental situations and moderate environmental knowledge (Huang and Yore, 2003).

In all these studies, affective variables appear to feature strongly to influence children's responsible environmental behaviour than the cognitive variable. For example, the Science And Scientists (SAS) study investigated 13-year-old pupils about what they would like to learn about in school science lessons, environmental topics scored below average interest among pupils in most Western countries (Sjøberg, 2000b, 2002a).

Most of the studies in the affective domain regarding environmental issues abound in the developed countries and are regularly published in science education journals. However, in Ghana, it appears there is paucity of research in this area. There is, at least, an obvious gap to be bridged here. This study hopes to contribute in addressing that.

The present study focuses on affective dimensions, such as attitude, concern, beliefs, values and emotional disposition towards environmental challenge issues in Ghana.

\section{Objective/Purpose of the study}

The purpose of this study is to investigate the views of JSS pupils in the Central Region about their concern of environment issues. The question guiding this study is: What views do these pupils hold about environmental challenge issues?

\section{Significance of the study}

Environmental problems in developing countries like Ghana, has continued to exist as a major challenge due to human activity. Accra, the capital of Ghana and other metropolis/district capitals are more faced with this challenge as well as the destruction of the natural environment and resources in the countryside. These areas are the economic nerve centres of this country and are stressed with environmental degradation due to overpopulation, lack of proper environmental practices and the poor environmental education knowledge of its younger generation.

Lack of proper method of educating the school children is yet to be tackled to bring about significant change in attitude that will produce favourable action towards the environment. It is therefore imperative to assess pupils' attitude to the environmental challenges to serve as a baseline study in the development of an effective instructional method of environmental education for the schools.

This study is also significant in that it contributes to the knowledge base about pupils' understandings of the environment. In addition, it is essential for research in environmental education to identify pupils' conceptions and understandings about the environment. Through 
this, it is hoped the Ghanaian society might achieve the development of an informed population that respect the values of a sustainable development.

\section{The ROSE project}

The ROSE is an international comparative research project meant to shed light on affective factors of importance to the learning of science and technology as perceived by the learners of about 15 year-old cohorts and also to stimulate discussions about context-based science curriculum. The ROSE project is organized by Svein Sjøberg and Camilla Schreiner, at The University of Oslo and is supported by the Research Council of Norway. The ROSE study involves about 40 countries, including Ghana.

Reports and details of the ROSE project including questionnaire and information about countries involved are found in Schreiner and Sjøberg (2004) and also available at web site (http://www.ils.uio.no/forskning/rose/). The above sources look at the issues of technicality and methodology regarding rational, design, piloting and deployment of the ROSE questionnaire, including reliability, validity and the use of Likert scale. Key international research institutions and individuals including the author of this paper have worked jointly on the development of theoretical perspectives, research instruments for data collection and analysis.

\section{Methodology}

\section{Data collection and analysis}

The data collection strategy for this study was a standard survey methodology within the quantitative research tradition. The study was a descriptive survey that went beyond the descriptive to the interpretive in order to provide explanations of patterns and relationships of the results obtained. The ROSE questionnaire includes among other themes, a list of items that has the theme "Me and the environmental challenges"' (see Appendix A). This theme has 18 statements on some environmental issues and pupils were asked to indicate the extent to which they agree with the statements on a 4-point Likert-type scale which goes from 'Disagree' to 'Agree'. The theme assesses pupils' attitudes and their sense of responsibility on environmental issues.

The responses from the ROSE questionnaire on the above theme were analysed through the use of SPSS version 12.0.1 for Windows (SPSS Inc., 2003) and Excel. Descriptive statistics and $t$ test were conducted on the data. In this study, the characteristics of descriptive statistics were used to examine JSS pupils' views about environmental challenges as they relate to science education. An independent sample 2-tailed $t$-test was used to explore the statistical significance of the differences in the items' mean. The conventional $p \leq 0.05$ level of probability was used as the basis for reporting the differences in means between boys' and girls' scores

The middle point of the 4-point Likert-type scale is regarded as a mean score of 2.5, and may represent a "neutral' position. For these items, it represents the mid-point of the scale since the scale ranges from "Disagree" which is coded as 1 to "Agree" coded 4 (Disagree $=1$, Slightly Disagree $=2$, Slightly Agree $=3$ and Agree $=4$ ). The value representing a 'neutral' position was used in this study to indicate a position in their responses where respondents, for example, are neither in disagreement nor agreement with a statement. A mean value above or below 2.5 gives a general picture of agreement or disagreement among pupils with a statement. This was done to make comparisons of different profiles very simple and straightforward. However, it 
must be noted that a mean value above or below 2.5 does not imply that all pupils agreed or disagreed with a statement, but the majority were.

\section{Population and Sample}

The target population consisted of all the pupils at the last year of the compulsory schooling in the Central Region of Ghana in the year 2003. It is the third year in Junior Secondary School (JSS 3 or ninth grade).

In selecting the sample of pupils that participated in this study, all the twelve (12) districts in the Central Region of Ghana were considered. A total of 1027 pupils in JSS 3 from 24 schools were involved. Twenty-four (24) schools from the twelve districts in the Central Region of Ghana were selected. The schools are representative of urban and rural settlements. Two schools, one each from urban and rural areas were selected from every district.

A stratified random sampling technique was used to choose the schools. A table of random numbers was used to select the schools. The numbers of male and female pupils that took part in this study were 551 and 476 respectively.

In selecting a school in an urban setting the following criteria were considered: Localities of 5000 persons and above have been classified as urban since 1960 (GIR, 1994). Secondly, an urban setting in Ghana is characterised by a number of social amenities more than that of a rural location; such as electricity, hospital, pipe borne water, efficient postal system, good road layouts, police station and internet facility. All the district capitals are characteristics of urban settlements. All the schools from the urban settings for this study were therefore purposively selected from the district capitals to ensure uniformity.

The Regional Education Director was contacted, and school district approval was acquired. In each district, the District Education Office provided names of all the schools and with the help of the office staff they were clustered into urban and rural schools.

\section{Results and Discussion}

Referring to Figures 1 and 2 generally, there was some similarity in pattern of agreement with statements. However, to what extent they did agree or disagree with a statement varied in levels. The responses indicated a mean range of 3.35 to 2.09 for boys and 3.27 to 2.23 for girls. When mean scores were considered for each statement, there were few of them that both boys and girls showed some levels of disagreement with mean values less than 2.5.

From the two diagrams, boys and girls were both in agreement with all the statements except: "Animals should have the same right to life as people", "Environmental problems are exaggerated", "Environmental problems make the future of the world look bleak and hopeless", "Environmental problems should be left to experts". Both boys and girls would want to practice responsible environmental behaviour and appeared to associate themselves with the statement that people need to care more about the protection of the environment. 


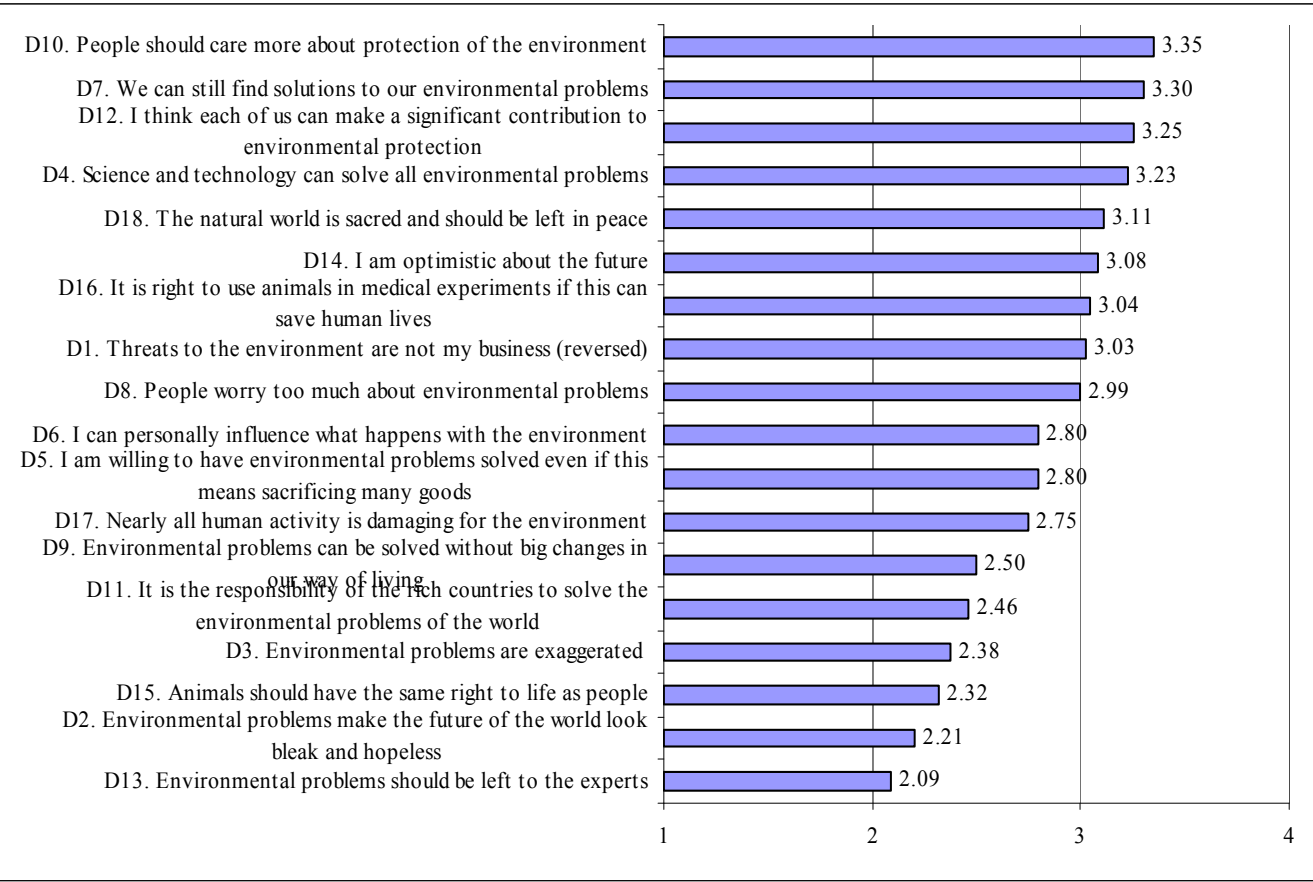

Figure 1

Boys' responses on attitude towards the environmental issues.

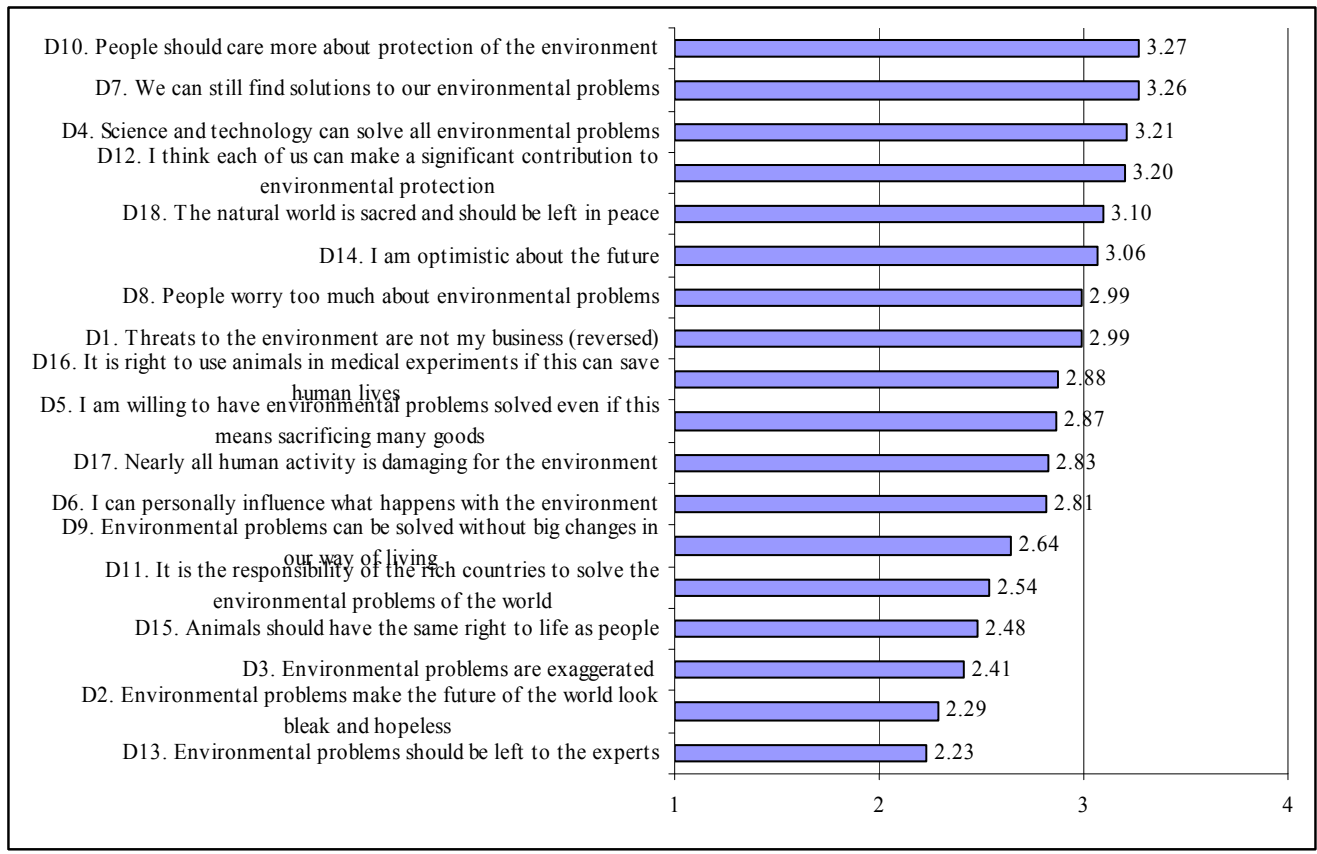

Figure 2

Girls' responses on attitude towards the environmental concerns

They also had a strong belief that threats to the environment should be the concern of everyone. They subscribed to useful environmental actions by individuals thereby indicating that, nearly all human activity damage the environment. They seemed to show optimism about the environment and strongly agreed that solutions to the environmental problems can be found and hence pupils appeared to disagree that environmental problems make the future of the world look bleak and hopeless. This finding is in line with some preliminary results from the analyses of the Norwegian ROSE data, which involved 1200 fifteen-year-old Norwegian pupils on how they relate to environmental challenges (see Schreiner and Sjøberg, 2003). Schreiner and Sjøberg confirmed the pupils' general concern about the environment. However, Ghanaian 
pupils were also interested to learn environmental education as school science subject (Anderson et al., In print).

Most Ghanaian pupils disagreed that environmental problems are exaggerated. In line with this, they are likely to be motivated for solving environmental problems. The motivation to solve environmental problems is also seen in the pupils agreeing with the statement that individuals can make a significant contribution to environmental protection. They were also in disagreement with the statements that it is the responsibility of the rich countries to solve the environmental problems of the world and also to leave environmental problems to the experts. This agrees with the findings of a study involving elementary school children of the United Kingdom aged between 11 and 13 years. All the children assert the individual responsibility for the environment and not others or the government (Bonnet and Williams, 1998). However, in this study, Ghanaian pupils in addition expressed positive views about the role of science and technology in solving environmental problems. This is confirmed by pupils' strong agreement with a statement that science and technology can solve all environmental problems; it is therefore not unexpected that pupils expressed a high level of interest in technology education (Anderson, 2007).

It might seem that boys and girls in Ghana would want to be active participants in keeping the balance between quality of life and the environment. Their responses indicated a willingness to have environmental problems solved even if this means sacrificing many goods. They also strongly agreed that the natural world is sacred and should be left in peace. It seems Ghanaian pupils perceive human beings to be much more important than animals, as they disagreed that animals should have the same right to life as people. Perhaps, this observation is consistent with pupils' responses that indicated a strong agreement with a statement that it is right to use animals in medical experiments if this can save human lives.

Also, both groups of pupils were of the opinion that the natural world is sacred and should be left in peace. It becomes apparent that the positive attitudes of pupils towards environmental challenge issues cut across all countries, but of varying degree (see Szagum and Pavlov, 1995) and that the environmental matters appear to be one of the most pressing topical socio-scientific issues of the global world. The fact is that many pupils from different cultures continue to show concerns for the future of the globe (see Schreiner and Sjøberg, 2003; Bonnet and Williams, 1998).

The pattern of the responses to the issue of the natural world as sacred can be interpreted in a number of ways. One is likely to interpret the response to mean that in a country where it appears there is strong adherence to religious and superstitious beliefs, the majority of pupils are likely to agree strongly with the statement that the natural world is sacred and should be left in peace. Perhaps, these pupils may tend to think that sacredness is associated with holiness, religion or connected with God in a special way. This might have influenced their opinions. But the question is: can religion instead of science be used to influence pupils' attitudes towards the environmental challenges facing many countries, especially the less developed countries? I do not intend to answer this important question; however, it may be an interesting question for further research.

There were some gender differences in opinions about some environmental challenge issues that were marked. There were ten out of the eighteen statements which showed statistically significant differences at $\mathrm{p}$-value of 0.05 . Seven of the issues characterized most of the girls and majority of the boys were more attracted to three (see Appendix B). 
It is important to note that members of both groups reported high or low preference levels in some similar items, but to some extent differed in the degree of preference. This must be seen in the light of differences between boys and girls. With large samples, like one in this study, even very small differences between mean scores of groups can become statistically significant. This does not mean that the difference has any practical, theoretical or educational significance (Pallant, 2001). However, it is noteworthy commenting on the differences in order to characterize different interest profiles.

\section{Conclusions and Implications}

\section{Conclusions}

The majority of pupils in the sample, irrespective of the gender, shared the same sentiments towards environmental protection issues. For example, the respondents agreed that science and technology can solve all environmental problems; the natural world is sacred and should be left in peace. They agreed that the solutions to our environmental problems can still be found. Despite their optimism about the future of the globe, they also appeared to maintain that people should care more about the protection of the environment. Their positive attitudes towards environmental challenges could be seen in their strong agreement levels shown with the statement that the threats to the environment are everyone else business. They also believed that each of us can make a significant contribution to environmental protection.

Ghanaian pupils perceived human beings to be much more important than animals, as they disagreed that animals should have the same right to life as people. They further agreed strongly that it is right to use animals in medical experiments if this can save human lives. An interesting aspect of Ghanaian pupils' concerns for environmental protection issues is that they also showed enthusiasm for environmental education studies perhaps, in order to gain knowledge in environmental protection issues.

In summary, most of the pupils appeared to:

- have optimism for the future of the globe

- believe that they can influence the future of the world but showed no strong commitment in sacrificing some goods for environmental problems to be solved.

- think that environmental protection is important for society and must be the responsibility of every citizen to be part of the solution.

- be interested to engage in environmental issues

- show enthusiasm for environmental education (Anderson et al, 2006)

\section{Implications}

The construction of new knowledge in science is strongly influenced by prior knowledge. It is also a process where motivation and interest in the subject matter may enhance or hinder such construction to take place.

This implies that teaching in general must also be based on the knowledge of pupil's affective dispositions. In this study it was found that pupils have attitudes, aspirations, motivation and capabilities to act regarding environmental challenge issues. As mentioned earlier, many research studies address the pupils' alternative conceptions or misconceptions in science. In these studies, researchers have found that school science learners hold ideas about science that are contrary to those of accepted science and hence in school science (Duit, 2004); and less 
about their attitudes, aspirations, motivation and capabilities to act regarding environmental issues.

In Ghana, the teaching of environmental education has been going on for some time now but unfortunately it appears there has not been any effort to assess the impact of environmental behaviour of pupils. Such a review is necessary to identify gaps in delivering effective environmental education.

It is possible in the integrated approach to environmental education for well trained teachers in environmental education to relate whatever topics they are teaching to environmental protection and management. There is therefore a great need for science teachers and teacher trainees to be exposed to more training regarding environmental challenge issues. This might position them better to accommodate or reflect learners' views during everyday classroom teaching to make environmental education appeal to learners. They must have sufficient knowledge about the science of the environment, about possible adequate actions in terms of personal lifestyle, technical solutions and political measures and also about possible channels of influence through politics, government and non-governmental organizations (Schreiner and Sjøberg, 2005).

Findings from the analysis of data in this study therefore give us as science educators, a deeper understanding of the views pupils hold about environmental challenge issues. What is crucial now is the way the topics in the environmental education are taught and presented to pupils. Though the empirical data do not give knowledge about the level of conceptual understanding of scientific ideas and concepts regarding environmental issues, my point of departure is that pupils' learning of ideas and concepts can be improved when more attention is given to the affective dimensions like attitudes, beliefs, values, appreciation or interest.

Pre-service programmes should help prospective teachers acquire the necessary skills of conducting environmental issue-related activity in the class. The prospective teachers should be guided in such a way that they could master the use of teaching strategies such as discussion, role-play, drama, group activity, in which learners are encouraged to express their understanding of a responsible environmental behaviour through participation and dialoguing. Dialogue, for example, assists learners to develop their reasoning abilities through argumentation (Nevo, 1995). It is imperative that both in-service and pre-service teachers gain appropriate knowledge and understanding of the views pupils hold about environmental challenge issues and to apply appropriate methods of instruction.

Teachers' belief about and their role as teachers in environmental challenge issues will have to be studied. With this knowledge, teacher educators could equip and motivate teacher trainees with skills that will allow them during their teaching to employ innovative, learner centered teaching-learning methods. This is because teachers who are themselves not environmentally conscious or have positive attitudes towards the environment might not be motivated enough to improve on the existing level of interest, belief, hope and concern with regard to environmental challenge issues in their classrooms.

As a science educator, I am also of the opinion that rational planning and improvement of society through education need to be based on research evidence. The results and findings of this study are likely to inform stakeholders in education when the contents and framing of the science curriculum are opened for negotiations and change. Improving on the prevailing affective dispositions of pupils could not take place only in the classroom, but also in the improving of the science curriculum to re-establish context, relevance, meaning and significance of science learning based on changing values, concerns, interests, priorities, hopes and aspirations of an individual towards the environment. 


\section{References}

Anderson, I.K. (2007). Relevance of Science Education: as seen by Pupils in Ghanaian Junior Secondary Schools. (Unpublished Ph.D. thesis). Cape Town: University of the Western Cape.

Anderson, I.K., Sjøberg, S. \& Mikalsen, Ø. (In print). What kinds of science and technology do pupils in Ghanaian junior secondary schools want to learn about? Some results and comparisons based on the international ROSE study. In C. Julie and Mikalsen, Ø. (eds), Some Developments in Research in Science and Mathematics Education in Sub-Saharan Africa. Cape Town: University of Western Cape.

Bonnet, M. \& Williams, J. (1998). Environmental education and primary children's attitudes towards nature and environment. Cambridge Journal of Education, 28, 159-175.

EPA (1995). Environmental Protection Agency. Survey on the state of Environmental Education in Ghanaian Schools. Accra, Ghana.

GIR (1994). Ghana Information Resource. Ghana Urban-Rural Disparities. Available at http://reference.com/country-guide-study/ghana/ghana44.html (accessed 30-06-05).

Huang, H. P \& Yore, L.D. (2003). A comparative study of Canadian and Taiwanese grade 5 children's environmental behaviours, attitudes, concerns, emotional dispositions, and knowledge. International Journal of Science and Mathematics Education, 1 (3), 419-448.

National Research Council (NRC) (1996). National science education standards. Washington, DC: National Academy Press.

Nevo (1995). School based evaluation - A dialogue for school improvement. Oxford: Pergamon.

Pallant, J. (2001).SPSS survival manual: A step by step guide to analysis using SPSS for Windows (version 10). Open University Press. Buckingham.

Reid, I. \& Sa'di, I. (1997). Jordanian and British primary schoolchildren's attitudes towards the environment. Educational Studies, 23, 473-480. Bonnet, M. and Williams, J. (1998). Environmental education and primary children's attitudes towards nature and environment. Cambridge Journal of Education, 28, 159-175.

Schreiner, C. \& Sjøberg, S. (2003). Optimists or pessimists? How do young people relate to environmental challenges? Available: http://www.ils.uio.no/forskning Paper presented at the ESERA (European Science Research Association) conference in Noordwijkerhout, The Netherlands.

Schreiner, C. \& Sjøberg, S. (2005). Empowered for action? How do young people relate to environmental challenges. (Avalable: http://www.ils.uio.no/forskning/rose/) Dept. of Teacher Education and School Development. University of Oslo, Norway

Schreiner, C., \& Sjøberg, S. (2004). Sowing the seeds of ROSE. Background, Rationale, Questionnaire Development and Data Collection for ROSE (The Relevance of Science Education) - a comparative study of students' views of science and science education. Acta Didactica.(4/2004) (ISBN 82-90904-79-7): Dept. of Teacher Education and School Development. University of Oslo, Norway 
Sjøberg, S. (2000b). Science and Scientists: The SAS-study. Cross-cultural evidence and perspective on pupils interests, experiences and perceptions-Background, development and selected results.. Acta Didactica. (1/2000). Dept. of Teacher Education and School Development. University of Oslo

Sjøberg, S. (2002a). Science for the children? A report from the Science and Scientists-project. Acta Didactica. (1/2002) Dept. of Teacher Education and School Development. University of Oslo

Statistical Package for Social Sciences (SPSS) Inc. (2003). SPSS for Windows, Version 12.0.1

Szagun, G. \& Pavlov, V. (1995). Environmental awareness. Youth \& Society, 27, 93-112.

\section{Appendices}

Appendix A

Meeting the environmental challenges

To what extent do you agree with the following statements about problems with the environment (pollution of air and water, overuse of resources, global changes of the climate etc.)? (Give your answer with a tick on each line. If you do not understand, leave the line blank.)

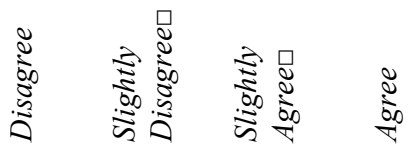

1. Threats to the environment are not my business

2. Environmental problems make the future of the world look bleak and hopeless

3. Environmental problems are exaggerated

4. Science and technology can solve all environmental problems.

5. I am willing to have environmental problems solved even if this means sacrificing many goods

6. I can personally influence what happens with the environment

7. We can still find solutions to our environmental problems

8. People worry too much about environmental problems

9. Environmental problems can be solved without big changes in our way of living.

10. People should care more about protection of the environment.

11. It is the responsibility of the rich countries to solve the environmental problems of the world

12. I think each of us can make a significant contribution to environmental protection

13. Environmental problems should be left to the experts

14. I am optimistic about the future

15. Animals should have the same right to life as people 
16. It is right to use animals in medical experiments if this can save human lives

17. Nearly all human activity is damaging for the environment.

18. The natural world is sacred and should be left in peace

\section{Appendix B}

\section{Gender differences in pupils' views about environmental challenges}

Mean values and standard deviation (SD) for girls and boys on the whole list of experiences. The list is sorted by gender difference in ascending order. Items where there is a statistically significant $(p<0.05)$ difference, $p$-values are in boldface. Positive difference (at the bottom part of the list) means that girls have higher responses

\begin{tabular}{|c|c|c|c|c|}
\hline Statements on environmental challenges & $\begin{array}{c}\text { Girls } \\
\text { Mean(SD) }\end{array}$ & $\begin{array}{c}\text { Boys } \\
\text { Mean(SD) }\end{array}$ & 龸 & p-value \\
\hline D14. I am optimistic about the future & $2.97(1.02)$ & $3.22(1.12)$ & -0.25 & 0.001 \\
\hline $\begin{array}{l}\text { D2. Environmental problems make the future of } \\
\text { the world look bleak and hopeless }\end{array}$ & $2.16(1.14)$ & $2.38(1.16)$ & -0.22 & 0.002 \\
\hline D3. Environmental problems are exaggerated & $2.33(0.99)$ & $2.48(1.13)$ & -0.15 & $\mathbf{0 . 0 3 1}$ \\
\hline $\begin{array}{l}\text { D1. Threats to the environment are not my } \\
\text { business }\end{array}$ & $2.97(1.17)$ & $3.07(1.12)$ & -0.10 & 0.156 \\
\hline $\begin{array}{l}\text { D6. I can personally influence what happens with } \\
\text { the environment }\end{array}$ & $2.77(1.02)$ & $2.86(1.12)$ & -0.09 & 0.214 \\
\hline $\begin{array}{l}\text { D17. Nearly all human activity is damaging for the } \\
\text { environment }\end{array}$ & $2.77(1.05)$ & $2.82(1.13)$ & -0.05 & 0.467 \\
\hline $\begin{array}{l}\text { D13. Environmental problems should be left to the } \\
\text { experts }\end{array}$ & $2.14(1.07)$ & $2.18(1.14)$ & -0.04 & 0.608 \\
\hline $\begin{array}{l}\text { D18. The natural world is sacred and should be left } \\
\text { in peace }\end{array}$ & $3.11(1.08)$ & $3.1(1.13)$ & 0.01 & 0.889 \\
\hline $\begin{array}{l}\text { D9. Environmental problems can be solved } \\
\text { without big changes in our way of living }\end{array}$ & $2.59(1.21)$ & $2.52(1.19)$ & 0.07 & 0.400 \\
\hline $\begin{array}{l}\text { D5. I am willing to have environmental problems } \\
\text { solved even if this means sacrificing many } \\
\text { goods }\end{array}$ & $2.88(1.1)$ & $2.75(1.18)$ & 0.13 & 0.072 \\
\hline $\begin{array}{l}\text { D11. It is the responsibility of the rich countries to } \\
\text { solve the environmental problems of the } \\
\text { world }\end{array}$ & $2.55(1.24)$ & $2.42(1.25)$ & 0.13 & 0.120 \\
\hline $\begin{array}{l}\text { D16. It is right to use animals in medical } \\
\text { experiments if this can save human lives }\end{array}$ & $3.03(1.08)$ & $2.87(1.2)$ & 0.16 & 0.027 \\
\hline $\begin{array}{l}\text { D4. Science and technology can solve all } \\
\text { environmental problems }\end{array}$ & $3.3(1.01)$ & $3.11(1.13)$ & 0.19 & 0.007 \\
\hline $\begin{array}{l}\text { D15. Animals should have the same right to life as } \\
\text { people }\end{array}$ & $2.49(1.23)$ & $2.25(1.26)$ & 0.24 & 0.002 \\
\hline $\begin{array}{l}\text { D7. We can still find solutions to our } \\
\text { environmental problems }\end{array}$ & $3.42(0.92)$ & $3.09(1.04)$ & 0.33 & 0.000 \\
\hline $\begin{array}{l}\text { D12. I think each of us can make a significant } \\
\text { contribution to environmental protection }\end{array}$ & $3.37(0.88)$ & $3.01(1.09)$ & 0.36 & 0.000 \\
\hline $\begin{array}{l}\text { D10. People should care more about protection of } \\
\text { the environment }\end{array}$ & $3.47(0.87)$ & $3.08(1.09)$ & 0.39 & 0.000 \\
\hline $\begin{array}{l}\text { D8. People worry too much about environmental } \\
\text { problems }\end{array}$ & $3.16(1.05)$ & $2.75(1.17)$ & 0.41 & 0.000 \\
\hline
\end{tabular}

